Published in final edited form as:

Immunol Res. 2009 ; 43(1-3): 98-108. doi:10.1007/s12026-008-8053-x.

\title{
Innate immune recognition of nucleic acids
}

\section{Tsan Xiao}

Structural Immunobiology Unit, Laboratory of Immunology, National Institute of Allergy and Infectious Diseases, National Institutes of Health, 4 Memorial Drive, Building 4, Room 138, Bethesda, MD 20892-0430, USA

Tsan Xiao: Xiaot@niaid.nih.gov

\section{Abstract}

The innate immune system employs a number of pattern recognition receptor families in response to DNAs and RNAs, either from invading microbes or within the hosts. These include the Tolllike receptors (TLRs), the retinoic acid inducible gene I (RIG-I) like receptors (RLRs), and the nucleotide-binding domain leucine-rich repeat/NOD-like receptor (NLRs), among other potential sensors in the cytoplasm. These receptors are composed of modular domain architecture, with ligand binding/sensing domains and signaling domains regulated either through dimerization/ oligomerization, or conformational changes directed by enzymatic activities. Signaling pathways from different families of receptors converge on their respective common adapter proteins and lead to activation of transcription factors or caspases. Many of these receptors induce orchestrated responses to similar ligands from different cell types, resulting in redundant and complementary immunity to infections. This highly efficient defense system is a double-edged sword: inappropriate reaction to host ligands leads to compromised innate tolerance and autoimmune diseases. Structural studies of innate immune receptors and their signaling pathways are essential in our understanding of pattern recognition mechanisms and design of more efficient vaccine adjuvants.

\section{Keywords}

Innate immune response; Pattern recognition receptors; Nucleic acids; Signal transduction; Antiviral defense; Autoimmunity; Vaccine adjuvants

\section{Introduction}

The ancient innate immune system provides the first line of defense against infection. This is dependent on various interacting cell types such as dendritic cells (DCs) and macrophages that are capable of detecting invading pathogens, responding to the infections through secretion of proinflammatory cytokines, chemokines, and interferons, upregulating expression of co-stimulatory molecules, and processing and presenting antigens to naïve $\mathrm{T}$ cells to activate the adaptive immune system. The power of the innate immune system has been harnessed to great public health benefits since the first published case of vaccination in the late eighteenth century [1]. Nonetheless, the underlying molecular mechanisms of innate immune recognition only started to emerge in the last decade, when major families of innate immune receptors, or the pattern recognition receptors (PRRs), were identified and their functions characterized [2-5]. PRRs were originally proposed to recognize pathogen-

(c) GovernmentEmployee: National Institutes of Health 2008 
associated molecular patterns (PAMPs), which implied inherent distinction of chemical "patterns" between hosts and pathogens, or "self" versus "non-self" recognition. It is now realized that PAMPs are present in both pathogenic and symbiotic microbes [6], and many of the PRRs are capable of responding to host molecules [7, 8]. This is particularly significant for those PRRs that recognize universal components of life such as nucleic acids, the activation of which poses potential threat of autoimmune diseases [9]. Here I will focus on these nucleic acid-recognizing PRRs, namely, the endosomal Toll-like receptors (TLRs), the cytoplasmic RLRs, and a member of the NLR family, as well as a recently identified cytoplasmic DNA sensor containing Z-DNA binding domains (Fig. 1).

\section{The endosomal TLRs}

The TLRs are a major family of membrane-bound PRRs [3, 4]. TLRs 3, 7, 8, and 9 are mainly implicated in antiviral defense because of their roles in the recognition of viral nucleic acids, delivered inside the cells through either endocytosis or autophagy [10,11]. In accordance, they are highly expressed in DCs, particularly plasmacytoid DCs (pDCs), the primary source of type I interferons in antiviral immunity [12]. TLR7 is activated by ssRNA viruses such as influenza virus and vesicular stomatitis virus (VSV) [10]. Both TLR7 and TLR8 are activated by HIV-1-derived uridine-rich RNAs [13]. TLR9 is essential for type I interferon production in response to DNA viruses such as herpes simplex virus, murine cytomegalovirus (MCMV), and adenovirus. TLR3 recognizes influenza virus, vaccinia virus, flavivirus, and MCMV [10, 12]. It contributes to immune protection against MCMV infection, nonetheless promotes the pathogenesis of infections by influenza virus and vaccinia virus through initiation of excessive inflammation [14]. The protective role of TLR3 during flavivirus infection is still controversial $[15,16]$.

The ability of these TLRs to respond to a particular type of virus is reflected by their ligandbinding specificities. For example, TL3 and 7 recognize double-stranded (ds) and singlestranded (ss) RNAs, respectively [17, 18]. TLR8 is a close paralog of TLR7 and there appears to be functional redundancy between these two receptors. Both TLR7 and 8 also recognize small synthetic ligands such as guanine nucleoside analog R-848 [19]. TLR9 is activated by ssDNAs with natural phosphodiester (PD) backbones independent of specific sequence and base modifications, whereas in the context of artificial phosphorothionate (PS) backbones, unmethylated cytosine-phosphate-guanine motifs are indispensable for activation [20]. In light of the significant impact of DNA backbones on the sequence requirement of TLR9 stimulation, the previous reports of various classes of oligodeoxyribonucleotides (ODNs) using PS and/or PS/PD hybrid backbones [21] may have to be reevaluated to differentiate the contributions of backbones and/or sequences to TLR9 stimulation. Moreover, TLR9 stimulation by ODNs is also dependent on cell types and aggregation states of ODNs. A recent study using conditional knock-out of MyD88 in DCs shows that MyD88-deficient DCs and other wild-type innate cells fail to induce inflammatory response to "naked" TLR9 ligands. In contrast, stimulation with lipidpackaged or aggregated forms of ODNs activates non-DC innate cells such as macrophages and natural killer cells and thus compensate for the MyD88-deficient DCs in initiation of adaptive immune response [22]. This illustrates distinct recognition of different forms of the same ligands by TLR9, as well as variable activation mechanisms of the same receptors in diverse cell types.

The antiviral functions of the nucleic acid-binding TLRs are correlated with their unique subcellular environments. TLR3, 7, 8, and 9 are present in the endoplasmic reticulum (ER) and are delivered to the endosomes through their association with ER membrane protein UNC93B1 [23, 24]. This strategic compartmentalization and trafficking of TLRs appears to have evolved to prevent inadvertent reaction to host nucleic acids. However, exceptions 
have been reported for TLR9 and TLR3 in their cellular localization. Using flow cytometry techniques and TLR9 peptide competition studies, Eaton-Bassiri et al. [25] reported expression of TLR9 in human peripheral blood mononuclear cells and tonsil B cells, suggesting a role of TLR9 ligands in B-cell activation and differentiation into plasma cells. More recently, cell surface TLR3 expression and response to siRNAs was linked to its antiangiogenesis activities in immune privileged retina-choroid interface [26]. Furthermore, innate tolerance facilitated by compartmentalization of TLRs breaks down in autoimmune diseases. In patients with systemic lupus erythematosus, a nuclear DNA-binding protein high-mobility group box 1 facilitates self-DNA uptake in immune complexes containing auto-antibodies, thus inducing TLR9-dependent production of proinflammatory cytokines and interferons [7]. In psoriasis patients, an antimicrobial peptide LL37/CAMP packages self-DNA into a condensed structure that is delivered to early endosomal compartments and activates TLR9 [27]. In both cases, the presence of self-DNAs in extracellular milieu alerts the innate immune system to defective clearance of cell death, further exacerbate tissue damage by invoking proinflammatory responses.

\section{Signal transduction by the TLRs}

Ligand binding by TLRs at the extracellular or endosomal milieu initiates a signal transduction cascade in the cytoplasm that leads to activation of transcription factors nuclear factor kB (NF-kB), interferon regulatory factors (IRFs) and activating protein-1 (AP-1) [28]. Specific domain architecture of TLRs provides the basis for distinct functions within different cellular environment. TLRs consist of amino-terminal ligand-binding leucine-rich repeats (LRRs), a central transmembrane domain, and a carboxyl-terminal Toll/interleukin-1 receptor (TIR) domain. The TIR domains are responsible for signaling to cytoplasmic TIR domain-containing adapter proteins. X-ray crystal structures for the extracellular domains of TLR 1, 2, 3, and 4 show similar horseshoe-shaped solenoid assemblies and characterized a number of important receptor-ligand interactions for the TLR1-TLR2 heterodimer, TLR3 homodimer, and TLR4-MD2 complexes [29-33]. The common theme that emerged from these structures is that ligand binding by TLRs mediates receptor dimerization and potential conformational change, which results in close association of the transmembrane and cytoplasmic domains of the receptors. The juxtaposition of the cytoplasmic TIR domains and formation of dimers or oligomers provides a platform for the recruitment of TIR domain-containing adapters. Such a TIR domain signaling complex triggers downstream signaling events that lead to activation of gene expressions for proinflammatory cytokines and interferons [34].

The formation of homo- and hetero-typic TIR-TIR domain complexes among the TLRs and their adapters is a crucial event in TLR signaling pathways [35]. Severe immuno-deficiency has been attributed to mutations in the TIR domains, presumably due to defective signal transduction [3]. There are five TIR domain containing adapters in the TLR signaling pathways: MyD88 (myeloid differentiation primary response gene 88), TIRAP/MAL (TIR domain-containing adapter protein/MyD88-adapter like), TRIF/TICAM1 (TIR-domaincontaining adapter-inducing interferon- $\beta /$ TLR adapter molecule 1), TRAM/TICAM2, and SARM (sterile $\alpha$ - and armadillo-motif containing protein) [35]. SARM is the only negative regulator that functions to suppress TRIF signaling pathways. These adapters are differentially recruited to the TLRs to generate signaling specificity in response to various TLR ligands, with MyD88 as the central adapter molecule that is utilized by all TLRs except for TLR3. In fact, a number of microbial virulence factors that contain inhibitory TIR domains have evolved to specifically target MyD88 signaling pathways [36]. MyD88deficient mice are highly susceptible to infections by various viruses, bacteria, fungi, and parasites, whereas human patients with recessive MyD88 deficiency suffer from pyrogenic bacterial infections, particularly early in life [37]. These patients are nonetheless resistant to 
infections by most other pathogens, highlighting species differences in redundant immune functions by various families of PRRs (see the following section).

The TIR domains are 150-200 residue motifs composed of five $\beta$ strands surrounded by $\alpha$ helices and loops, as reported for the TIR domains of TLR1, TLR2, TLR10, and IL1RAPL [38-41]. In particular, the "BB," "DD" and "EE" loops have been proposed to reside at the TIR-TIR dimer interface. Mutation of a highly conserved proline residue on the BB loop of the TLR4 TIR domain renders the $\mathrm{C} 3 \mathrm{H} / \mathrm{HeJ}$ mice unresponsive to bacterial endotoxin [3, 42]. Peptidomimetic compounds based on the BB loop of MyD88 have been reported to interfere with MyD88-dependent signaling [43, 44]. A variant of the TIRAP TIR domain, Ser180Leu, in humans confers resistance to malaria, tuberculosis, and pneumococcal pneumonia, a likely consequence of altered TIRAP-mediated signaling from TLR2 and/or TLR4 [45]. Even though a number of docking models for the TIR-TIR domain complexes have been proposed, all of which focused on constructing interfaces centered on the BB and DD loops, a consistent mode of the TIR-TIR domain interaction has yet to emerge [35, 38]. Recently NMR structures of the TIR domain of MyD88 were deposited in the protein data bank. The BB loop of MyD88 TIR domain adopts a drastically different conformation compared with other TIR domain structures. It is not clear whether this represents a unique feature of the MyD88 TIR domain, nor is it apparent how the different BB loop conformations facilitate formation of specific TIR-TIR signaling complexes involving MyD88 homodimer or MyD88 in association with TLRs.

\section{RLRs as cytoplasmic RNA sensors}

In addition to the membrane-bound receptors described above, a number of cytosolic receptors for RNAs have evolved by the innate immune system to initiate antiviral responses. These include a new family of RNA helicase receptors referred to as RLRs: RIGI, melanoma differentiation factor-5 (MDA5), and laboratory of genetics and physiology-2 (LGP2) (Fig. 1) [10, 46]. Sensing of viral RNAs by RLRs activates IRFs and induces expression of interferons, which in turn upregulates expression of the above receptors, creating a powerful positive feedback. Mice lacking RIG-I are highly susceptible to infections by Japanese encephalitis virus, influenza virus, and VSV, whereas MDA5deficient mice succumb to encephalomyocarditis virus (EMCV), Theiler's encephalomyelitis virus, and mengovirus [47]. Enhanced susceptibility to EMCV was observed for LGP2-deficient mice [48].

Specific ligand recognition mechanisms have evolved for these RLRs to prevent or decrease basal activation by abundant host messenger, ribosomal, and transfer RNAs in the cytoplasm. 5' phosphate in ssRNAs has been shown to be the critical element for RIG-I stimulation but is largely absent from host mRNA and tRNA, and 5' phosphate observed in host $5 \mathrm{~S}$ rRNAs may be obscured by the bound ribosomal proteins $[49,50]$. In addition, RIGI binds short ( $\sim \mathrm{kb})$ dsRNA to a lesser extent compared with ssRNA. In comparison, MDA5 appears to prefer long $(>2 \mathrm{~kb})$ dsRNA and is implicated in recognizing long viral genomes or stable viral RNA duplexes formed as replication intermediates [51]. The molecular basis of these distinct ligand specificities for RIG-I and MDA5 is unclear, as is the ligand recognition mechanisms of the homologous receptor LGP2. LGP2 was initially identified as a suppressor of RIG-I signaling, but has been implicated in positive regulation of MDA5 signaling through a potential heterodimerization mechanism [48].

All three RLRs contain a DExD/H box helicase domain that binds ATP. The ATPase activity of their helicase domains is central to receptor activation and signaling [5]. Both RIG-I and LGP2, but not MDA5, contain a C-terminal repressor domain (RD) that maintains the receptors in a self-inhibited state in the absence of ligand binding [52]. The RD is also 
the primary binding site for RNA, which releases the receptors from self-inhibition through ATP-dependent conformational changes [53]. A well-defined subdomain called the Cterminal domain (CTD) within the RD was recently identified for all three RLRs and the crystal and NMR structures of RIG-I CTD were determined [54]. The structures illustrate a basic concave surface that is required for RNA binding and subsequent release of selfinhibition. Dimerization of CTD mediated by RNA binding was also demonstrated, suggesting an analogous mode of activation to that of TLR3 binding to dsRNA [54]. The signaling components of RIG-I and MDA5 reside at their N-terminal caspase activation and recruitment domains (CARDs), which interact with the CARD of their adapter molecule interferon $\beta$ promoter stimulator-1 (IPS-1) on the mitochondria outer membrane [55-59]. The mechanism of CARD-CARD interactions during RLR-mediated signaling remains unclear, though biophysical studies of CARD domains have suggested heterodimer formation of partner domains through complementary charge-charge interactions [60, 61]. The presence of tandem CARD domains in RIG-I and MDA5 and the complete absence of CARD domain in LGP2 hint at novel mechanisms of signaling regulation by RLRs compared with other known single CARD domain proteins.

\section{New nucleic acid sensors in the cytoplasm}

Recently, TLR-independent recognition of cytoplasmic DNAs $[62,63]$ and response to DNA vaccines $[64,65]$ have been reported. Interestingly, both microbial and host DNAs induce type I interferon expression, with right-handed B-form DNAs being more potent than left-handed Z-form DNAs [62]. Even though the exact identities of cytoplasmic DNA sensors remain controversial, several intriguing candidates have been proposed.

NLRP3 (CIAS1/cryopyrin/NALP3) was first identified in patients with familial cold autoinflammatory syndrome and Muckle-Wells syndrome [66]. Importantly, treatment of these patients with IL-1 receptor antagonists dramatically alleviates their symptoms [67], highlighting a prominent role of NLRP3 in pro-IL1 $\beta$ processing. NLRP3 belongs to a large family of cytoplasmic PRRs: the NLRs [68, 69]. Among these are NALPs (NACHT-, LRR-, and pyrin-domain-containing proteins), NLRC4/IPAF (ICE-protease-activating factor or CARD12 and CLAN), NOD proteins, and class II trans-activator (CIITA). The majority of NLRs utilize a central adapter protein ASC (apoptosis-associated speck-like protein containing a CARD) in their signaling pathways [70]. Activation of caspase-1 and subsequent pro-IL $1 \beta$ processing is mediated by the formation of a large protein complex composed of NLRs (such as NLRP1, NLRP3, or NLRC4), the adapter ASC and procaspase-1, collectively termed the "inflammasome" [71].

NLRP3 was recently implicated in sensing bacterial and viral RNA, although the evidence is debatable since the presence of ATP, another potent activator of procaspase-1, is required [72]. More convincing evidence was reported for NLRP3-dependent maturation of IL- $1 \beta$ in response to infection by adenovirus, a non-enveloped DNA virus [73]. In comparison, infection with empty viral capsids without DNA failed to induce IL- $1 \beta$ processing. Surprisingly, liposome-mediated transfection of viral, bacteria, fish, or human DNAs resulted in IL- $\beta$ maturation in the absence of NLRP3. Instead, the crucial adapter protein ASC is required, suggesting that other members of the NLR family may be involved in DNA sensing as well [73].

The exact mechanism of NLRP3 recognition of DNA is unclear, neither is its ability to respond to various other stimuli from endogeneous, microbial, and environmental sources, such as $\beta$-amyloid [74], uric acid crystals [75], asbestos [76], silica crystals, or aluminum salts, an adjuvant frequently used in human vaccines [77]. It should be emphasized that none of the reports have definitively characterized direct binding of NLRP3 to any of the above 
"ligands." Instead, a more likely scenario is indirect activation of NLRP3 through a common cellular stimulus, such as potassium efflux or elevated reactive oxygen species (ROS) level $[68,78,79]$, which may enhance the formation of NLRP3 inflammasome and activation of procaspase-1. Members of the NLR family are therefore often referred to as "sensors" instead of "receptors" because of the proposed indirect activation process.

Z-DNA binding protein 1 (ZBP1) was first identified as a tumor response gene that is highly expressed in lymphatic tissues [80, 81]. It contains $\mathrm{N}$-terminal $\mathrm{Z} \alpha$ and $\mathrm{Z} \beta$ domains known to stabilize and induce Z-forms of DNA and RNA. Such Z-DNA binding activity is also present in virulence factor E3L from vaccinia virus. Abrogation of the Z-DNA binding function of E3L significantly decreased viral pathogenicity, whereas replacing the mutant ZDNA binding domain of E3L with the Z $\alpha$ domain of ZBP1 restored viral lethality [82]. The role of ZBP1 in antiviral innate defense was underscored by recent reports that established its ability to induce type I interferon secretion in response to cytoplasmic DNAs [83]. However, gene knock-out studies suggested that innate immune response to DNA vaccines is independent of both ZBP1 and TLR9 [84]. This apparent inconsistency suggests that additional DNA sensors such as NLRP3 may play predominant roles under certain experimental settings, and different DNA recognition mechanisms may have redundant roles in innate immune responses.

\section{Future perspectives}

As discussed above, a prominent feature of the immune system is the built-in redundancy and complementarity from partially overlapping functions of different cell types and receptors/sensors that respond to various forms of stimuli. The power of redundancy perhaps evolves to ensure fail-safe response to infections; nonetheless it renders hosts vulnerable to autoimmune diseases precisely because the same stimuli such as nucleic acids are present in both pathogens and hosts.

Complementary and orchestrated innate immune response to nucleic acids is reflected by concurrent activation of different PRRs to the same stimuli, sometimes in various cell types. For example, pDCs respond to influenza virus infection through the recognition of ssRNA viral genome by TLR7, whereas RIG-I/IPS-1 pathway is activated by the same virus in fibroblasts and myeloid DCs. Abrogation of either pathway retained interferon response to viral infection, whereas deficiency in both leads to failed antiviral response and much higher viral titers [85]. It is also interesting to note that induction of influenza-specific B and T cell responses do appear to be more dependent on the TLR7/MyD88 pathway than the RIG-I/ IPS-1 pathway [85]. In contrast to the positive contribution by both TLR7 and RIG-I, activation of TLR3 by influenza virus promotes excessive inflammation and lethality in mice [14]. Therefore, the "net" outcome of immune response against a particular pathogen originates from elaborate interplay among various signaling pathways or networks.

A major motivation for studying innate immunity is the potential for better vaccine adjuvants through thorough understanding of the pattern recognition mechanisms. This requires detailed biophysical characterization of receptor:ligand interactions and structural studies of receptors in association with diverse ligands. Targeting nucleic acid-recognizing PRRs has become a particularly fertile field for vaccine adjuvant development because highly purified ligand analogs are readily available through chemical synthesis. Many of the nucleic acid analogs have been demonstrated to enhance both humoral and cellular immune responses. A well-studied example is TLR9 ligand ODNs that have been shown to be effective adjuvants not only in traditional prophylactic vaccination, but also in therapeutic vaccination against cancer and allergy because of their strong induction of Th1 polarization [86]. Future structural characterization of various ODNs in complex with TLR9 will reveal 
mechanisms of ligand-binding specificity, as well as molecular basis of agonistic or antagonistic effects of various classes of ODNs. Structures of signaling complexes containing adapter proteins MyD88, IPS-1, or ASC will furnish invaluable insights into the common determinants of respective signaling pathways. Structures of full-length receptors such as RIG-I in the presence and absence of ligands are crucial for our understanding of the mechanisms of self-inhibition and conformational changes involved in receptor activation. Biochemical and biophysical studies of NLRP3 and other NLR members will unravel the mystery of ligand sensing and indirect activation by potassium efflux or ROS. Ultimately, structural and molecular characterization of PRRs, ligands, signaling adapters, and their complexes will be instrumental in guiding the design of more efficient vaccine adjuvants for clinical applications.

\section{Acknowledgments}

The author is supported by the Division of Intramural Research of the National Institute of Allergy and Infectious Diseases, National Institutes of Health.

\section{References}

1. Jenner, E. An inquiry into the causes and effects of the variolae vaccinae, a disease discovered in some Western counties of England. London: Sampson Low; 1798.

2. Janeway CA Jr. Approaching the asymptote? Evolution and revolution in immunology. Cold Spring Harb Symp Quant Biol. 1989; 54(Pt 1):1-13. [PubMed: 2700931]

3. Poltorak A, He X, Smirnova I, Liu M-Y, Van Huffel C, Du X, et al. Defective LPS signaling in C3H/HeJ and C57BL/10ScCr mice: mutations in Tlr4 gene. Science. 1998; 282:2085-8. [PubMed: 9851930]

4. Medzhitov R, Preston-Hurlburt P, Janeway CA Jr. A human homologue of the Drosophila toll protein signals activation of adaptive immunity. Nature. 1997; 388:394-7. [PubMed: 9237759]

5. Yoneyama M, Kikuchi M, Natsukawa T, Shinobu N, Imaizumi T, Miyagishi M, et al. The RNA helicase RIG-I has an essential function in double-stranded RNA-induced innate antiviral responses. Nat Immunol. 2004; 5:730-7. [PubMed: 15208624]

6. Rakoff-Nahoum S, Paglino J, Eslami-Varzaneh F, Edberg S, Medzhitov R. Recognition of commensal microflora by toll-like receptors is required for intestinal homeostasis. Cell. 2004; 118:229-41. [PubMed: 15260992]

7. Tian J, Avalos AM, Mao SY, Chen B, Senthil K, Wu H, et al. Toll-like receptor 9-dependent activation by DNA-containing immune complexes is mediated by HMGB1 and RAGE. Nat Immunol. 2007; 8:487-96. [PubMed: 17417641]

8. Akira S, Uematsu S, Takeuchi O. Pathogen recognition and innate immunity. Cell. 2006; 124:783801. [PubMed: 16497588]

9. Marshak-Rothstein A, Rifkin IR. Immunologically active autoantigens: the role of toll-like receptors in the development of chronic inflammatory disease. Annu Rev Immunol. 2007; 25:419-41. [PubMed: 17378763]

10. Pichlmair A, Reis e Sousa C. Innate recognition of viruses. Immunity. 2007; 27:370-83. [PubMed: 17892846]

11. Lee HK, Lund JM, Ramanathan B, Mizushima N, Iwasaki A. Autophagy-dependent viral recognition by plasmacytoid dendritic cells. Science. 2007; 315:1398-401. [PubMed: 17272685]

12. Kawai T, Akira S. Innate immune recognition of viral infection. Nat Immunol. 2006; 7:131-7. [PubMed: 16424890]

13. Meier A, Alter G, Frahm N, Sidhu H, Li B, Bagchi A, et al. MyD88-dependent immune activation mediated by human immunodeficiency virus type 1-encoded Toll-like receptor ligands. J Virol. 2007; 81:8180-91. [PubMed: 17507480]

14. Le Goffic R, Balloy V, Lagranderie M, Alexopoulou L, Escriou N, Flavell R, et al. Detrimental contribution of the Toll-like receptor (TLR) 3 to influenza A virus-induced acute pneumonia. PLoS Pathog. 2006; 2:e53. [PubMed: 16789835] 
15. Daffis S, Samuel MA, Suthar MS, Gale M Jr, Diamond MS. Toll-like receptor-3 has a protective role against West Nile virus infection. J Virol. August.2008 20 [Epub ahead of print].

16. Wang T, Town T, Alexopoulou L, Anderson JF, Fikrig E, Flavell RA. Toll-like receptor 3 mediates West Nile virus entry into the brain causing lethal encephalitis. Nat Med. 2004; 10:136673. [PubMed: 15558055]

17. Alexopoulou L, Holt AC, Medzhitov R, Flavell RA. Recognition of double-stranded RNA and activation of NF-kB by Toll-like receptor 3. Nature. 2001; 413:732-8. [PubMed: 11607032]

18. Diebold SS, Kaisho T, Hemmi H, Akira S, Reis e Sousa C. Innate antiviral responses by means of TLR7-mediated recognition of single-stranded RNA. Science. 2004; 303:1529-31. [PubMed: 14976261]

19. Heil F, Ahmad-Nejad P, Hemmi H, Hochrein H, Ampenberger F, Gellert T, et al. The Toll-like receptor 7 (TLR7)-specific stimulus loxoribine uncovers a strong relationship within the TLR7, 8 and 9 subfamily. Eur J Immunol. 2003; 33:2987-97. [PubMed: 14579267]

20. Haas T, Metzger J, Schmitz F, Heit A, Muller T, Latz E, et al. The DNA sugar backbone 2' deoxyribose determines toll-like receptor 9 activation. Immunity. 2008; 28:315-23. [PubMed: 18342006]

21. Higgins D, Marshall JD, Traquina P, Van Nest G, Livingston BD. Immunostimulatory DNA as a vaccine adjuvant. Expert Rev Vaccines. 2007; 6:747-59. [PubMed: 17931155]

22. Hou B, Reizis B, Defranco AL. Toll-like receptors activate innate and adaptive immunity by using dendritic cell-intrinsic and -extrinsic mechanisms. Immunity. 2008; 29:272-82. [PubMed: 18656388]

23. Latz E, Schoenemeyer A, Visintin A, Fitzgerald KA, Monks BG, Knetter CF, et al. TLR9 signals after translocating from the ER to CpG DNA in the lysosome. Nat Immunol. 2004; 5:190-8. [PubMed: 14716310]

24. Kim YM, Brinkmann MM, Paquet ME, Ploegh HL. UNC93B1 delivers nucleotide-sensing tolllike receptors to endolysosomes. Nature. 2008; 452:234-8. [PubMed: 18305481]

25. Eaton-Bassiri A, Dillon SB, Cunningham M, Rycyzyn MA, Mills J, Sarisky RT, et al. Toll-like receptor 9 can be expressed at the cell surface of distinct populations of tonsils and human peripheral blood mono-nuclear cells. Infect Immun. 2004; 72:7202-11. [PubMed: 15557645]

26. Kleinman ME, Yamada K, Takeda A, Chandrasekaran V, Nozaki M, Baffi JZ, et al. Sequence- and target-independent angiogenesis suppression by siRNA via TLR3. Nature. 2008; 452:591-7. [PubMed: 18368052]

27. Lande R, Gregorio J, Facchinetti V, Chatterjee B, Wang YH, Homey B, et al. Plasmacytoid dendritic cells sense self-DNA coupled with antimicrobial peptide. Nature. 2007; 449:564-9. [PubMed: 17873860]

28. O'Neill LA. How Toll-like receptors signal: what we know and what we don't know. Curr Opin Immunol. 2006; 18:3-9. [PubMed: 16343886]

29. Bell JK, Botos I, Hall PR, Askins J, Shiloach J, Segal DM, et al. The molecular structure of the Toll-like receptor 3 ligand-binding domain. Proc Natl Acad Sci U S A. 2005; 102:10976-80. [PubMed: 16043704]

30. Choe J, Kelker MS, Wilson IA. Crystal structure of human toll-like receptor 3 (TLR3) ectodomain. Science. 2005; 309:581-5. [PubMed: 15961631]

31. Jin MS, Kim SE, Heo JY, Lee ME, Kim HM, Paik SG, et al. Crystal structure of the TLR1-TLR2 heterodimer induced by binding of a tri-acylated lipopeptide. Cell. 2007; 130:1071-82. [PubMed: 17889651]

32. Kim HM, Park BS, Kim JI, Kim SE, Lee J, Oh SC, et al. Crystal structure of the TLR4-MD-2 complex with bound endotoxin antagonist Eritoran. Cell. 2007; 130:906-17. [PubMed: 17803912]

33. Liu L, Botos I, Wang Y, Leonard JN, Shiloach J, Segal DM, et al. Structural basis of toll-like receptor 3 signaling with double-stranded RNA. Science. 2008; 320:379-81. [PubMed: 18420935]

34. Jin MS, Lee JO. Structures of the Toll-like receptor family and its ligand complexes. Immunity. 2008; 29:182-91. [PubMed: 18701082]

35. O'Neill LA, Bowie AG. The family of five: TIR-domain-containing adaptors in Toll-like receptor signalling. Nat Rev Immunol. 2007; 7:353-64. [PubMed: 17457343] 
36. Cirl C, Wieser A, Yadav M, Duerr S, Schubert S, Fischer H, et al. Subversion of Toll-like receptor signaling by a unique family of bacterial Toll/interleukin-1 receptor domain-containing proteins. Nat Med. 2008; 14:399-406. [PubMed: 18327267]

37. von Bernuth H, Picard C, Jin Z, Pankla R, Xiao H, Ku CL, et al. Pyogenic bacterial infections in humans with MyD88 deficiency. Science. 2008; 321:691-6. [PubMed: 18669862]

38. Xu Y, Tao X, Shen B, Horng T, Medzhitov R, Manley JL, et al. Structural basis for signal transduction by the Toll/interleukin-1 receptor domains. Nature. 2000; 408:111-5. [PubMed: $11081518]$

39. Tao X, Xu Y, Zheng Y, Beg AA, Tong L. An extensively associated dimer in the structure of the C713S mutant of the TIR domain of human TLR2. Biochem Biophys Res Commun. 2002; 299:216-21. [PubMed: 12437972]

40. Khan JA, Brint EK, O’Neill LA, Tong L. Crystal structure of the Toll/interleukin-1 receptor domain of human IL-1RAPL. J Biol Chem. 2004; 279:31664-70. [PubMed: 15123616]

41. Nyman T, Stenmark P, Flodin S, Johansson I, Hammarstrom M, Nordlund P. The crystal structure of the human toll-like receptor-10 cytoplasmic domain reveals a putative signaling dimer. J Biol Chem. 2008; 283:11861-5. [PubMed: 18332149]

42. Sultzer BM. Genetic control of leucocyte responses to endotoxin. Nature. 1968; 219:1253-4. [PubMed: 4877918]

43. Bartfai T, Behrens MM, Gaidarova S, Pemberton J, Shivanyuk A, Rebek J Jr. A low molecular weight mimic of the Toll/IL-1 receptor/resistance domain inhibits IL-1 receptor-mediated responses. Proc Natl Acad Sci U S A. 2003; 100:7971-6. [PubMed: 12799462]

44. Loiarro M, Capolunghi F, Fanto N, Gallo G, Campo S, Arseni B, et al. Pivotal advance: inhibition of MyD88 dimerization and recruitment of IRAK1 and IRAK4 by a novel peptidomimetic compound. J Leukoc Biol. 2007; 82:801-10. [PubMed: 17548806]

45. Khor CC, Chapman SJ, Vannberg FO, Dunne A, Murphy C, Ling EY, et al. A Mal functional variant is associated with protection against invasive pneumococcal disease, bacteremia, malaria and tuberculosis. Nat Genet. 2007; 39:523-8. [PubMed: 17322885]

46. Ishii KJ, Koyama S, Nakagawa A, Coban C, Akira S. Host innate immune receptors and beyond: making sense of microbial infections. Cell Host Microbe. 2008; 3:352-63. [PubMed: 18541212]

47. Kato H, Takeuchi O, Sato S, Yoneyama M, Yamamoto M, Matsui K, et al. Differential roles of MDA5 and RIG-I helicases in the recognition of RNA viruses. Nature. 2006; 441:101-5. [PubMed: 16625202]

48. Venkataraman T, Valdes M, Elsby R, Kakuta S, Caceres G, Saijo S, et al. Loss of DExD/H box RNA helicase LGP2 manifests disparate antiviral responses. J Immunol. 2007; 178:6444-55. [PubMed: 17475874]

49. Hornung V, Ellegast J, Kim S, Brzozka K, Jung A, Kato H, et al. 5'-Triphosphate RNA is the ligand for RIG-I. Science. 2006; 314:994-7. [PubMed: 17038590]

50. Pichlmair A, Schulz O, Tan CP, Naslund TI, Liljestrom P, Weber F, et al. RIG-I-mediated antiviral responses to single-stranded RNA bearing 5'-phosphates. Science. 2006; 314:997-1001. [PubMed: 17038589]

51. Kato H, Takeuchi O, Mikamo-Satoh E, Hirai R, Kawai T, Matsushita K, et al. Length-dependent recognition of double-stranded ribonucleic acids by retinoic acid-inducible gene-I and melanoma differentiation-associated gene 5. J Exp Med. 2008; 205:1601-10. [PubMed: 18591409]

52. Saito T, Hirai R, Loo YM, Owen D, Johnson CL, Sinha SC, et al. Regulation of innate antiviral defenses through a shared repressor domain in RIG-I and LGP2. Proc Natl Acad Sci U S A. 2007; 104:582-7. [PubMed: 17190814]

53. Saito T, Gale M Jr. Differential recognition of double-stranded RNA by RIG-I-like receptors in antiviral immunity. J Exp Med. 2008; 205:1523-7. [PubMed: 18591413]

54. Cui S, Eisenacher K, Kirchhofer A, Brzozka K, Lammens A, Lammens K, et al. The C-terminal regulatory domain is the RNA 5'-triphosphate sensor of RIG-I. Mol Cell. 2008; 29:169-79. [PubMed: 18243112]

55. Kawai T, Takahashi K, Sato S, Coban C, Kumar H, Kato H, et al. IPS-1, an adaptor triggering RIG-I-and Mda5-mediated type I interferon induction. Nat Immunol. 2005; 6:981-8. [PubMed: 16127453] 
56. Potter JA, Randall RE, Taylor GL. Crystal structure of human IPS-1/MAVS/VISA/Cardif caspase activation recruitment domain. BMC Struct Biol. 2008; 8:11. [PubMed: 18307765]

57. Seth RB, Sun L, Ea CK, Chen ZJ. Identification characterization of MAVS, a mitochondrial antiviral signaling protein that activates NF-kappaB and IRF 3. Cell. 2005; 122:669-82. [PubMed: 16125763]

58. Meylan E, Curran J, Hofmann K, Moradpour D, Binder M, Bartenschlager R, et al. Cardif is an adaptor protein in the RIG-I antiviral pathway and is targeted by hepatitis C virus. Nature. 2005; 437:1167-72. [PubMed: 16177806]

59. Xu LG, Wang YY, Han KJ, Li LY, Zhai Z, Shu HB. VISA is an adapter protein required for virustriggered IFN-beta signaling. Mol Cell. 2005; 19:727-40. [PubMed: 16153868]

60. Qin H, Srinivasula SM, Wu G, Fernandes-Alnemri T, Alnemri ES, Shi Y. Structural basis of procaspase-9 recruitment by the apoptotic protease-activating factor 1. Nature. 1999; 399:549-57. [PubMed: 10376594]

61. Chou JJ, Matsuo H, Duan H, Wagner G. Solution structure of the RAIDD CARD and model for CARD/CARD interaction in caspase-2 and caspase-9 recruitment. Cell. 1998; 94:171-80. [PubMed: 9695946]

62. Ishii KJ, Coban C, Kato H, Takahashi K, Torii Y, Takeshita F, et al. A Toll-like receptorindependent antiviral response induced by double-stranded B-form DNA. Nat Immunol. 2006; 7:40-8. [PubMed: 16286919]

63. Stetson DB, Medzhitov R. Recognition of cytosolic DNA activates an IRF3-dependent innate immune response. Immunity. 2006; 24:93-103. [PubMed: 16413926]

64. Spies B, Hochrein H, Vabulas M, Huster K, Busch DH, Schmitz F, et al. Vaccination with plasmid DNA activates dendritic cells via Toll-like receptor 9 (TLR9) but functions in TLR9-deficient mice. J Immunol. 2003; 171:5908-12. [PubMed: 14634101]

65. Babiuk S, Mookherjee N, Pontarollo R, Griebel P, den Hurk S, Hecker R, et al. TLR9 -/- and TLR9 +/+ mice display similar immune responses to a DNA vaccine. Immunology. 2004; 113:114-20. [PubMed: 15312142]

66. Hoffman HM, Mueller JL, Broide DH, Wanderer AA, Kolodner RD. Mutation of a new gene encoding a putative pyrin-like protein causes familial cold autoinflammatory syndrome and Muckle-Wells syndrome. Nat Genet. 2001; 29:301-5. [PubMed: 11687797]

67. Hoffman HM, Rosengren S, Boyle DL, Cho JY, Nayar J, Mueller JL, et al. Prevention of coldassociated acute inflammation in familial cold autoinflammatory syndrome by interleukin-1 receptor antagonist. Lancet. 2004; 364:1779-85. [PubMed: 15541451]

68. Petrilli V, Dostert C, Muruve DA, Tschopp J. The inflammasome: a danger sensing complex triggering innate immunity. Curr Opin Immunol. 2007; 19:615-22. [PubMed: 17977705]

69. Ye Z, Ting JP. NLR, the nucleotide-binding domain leucine-rich repeat containing gene family. Curr Opin Immunol. 2008; 20:3-9. [PubMed: 18280719]

70. Masumoto J, Taniguchi S, Ayukawa K, Sarvotham H, Kishino T, Niikawa N, et al. ASC, a novel $22-\mathrm{kDa}$ protein, aggregates during apoptosis of human promyelocytic leukemia HL-60 cells. J Biol Chem. 1999; 274:33835-8. [PubMed: 10567338]

71. Martinon F, Burns K, Tschopp J. The inflammasome: a molecular platform triggering activation of inflammatory caspases and processing of proIL-beta. Mol Cell. 2002; 10:417-26. [PubMed: 12191486]

72. Kanneganti TD, Ozoren N, Body-Malapel M, Amer A, Park JH, Franchi L, et al. Bacterial RNA and small antiviral compounds activate caspase-1 through cryopyrin/Nalp3. Nature. 2006; 440:233-6. [PubMed: 16407888]

73. Muruve DA, Petrilli V, Zaiss AK, White LR, Clark SA, Ross PJ, et al. The inflammasome recognizes cytosolic microbial and host DNA and triggers an innate immune response. Nature. 2008; 452:103-7. [PubMed: 18288107]

74. Halle A, Hornung V, Petzold GC, Stewart CR, Monks BG, Reinheckel T, et al. The NALP3 inflammasome is involved in the innate immune response to amyloid-beta. Nat Immunol. 2008; 9:857-65. [PubMed: 18604209]

75. Martinon F, Petrilli V, Mayor A, Tardivel A, Tschopp J. Gout-associated uric acid crystals activate the NALP3 inflammasome. Nature. 2006; 440:237-41. [PubMed: 16407889] 
76. Dostert C, Petrilli V, Van Bruggen R, Steele C, Mossman BT, Tschopp J. Innate immune activation through Nalp3 inflammasome sensing of asbestos and silica. Science. 2008; 320:674-7. [PubMed: 18403674]

77. Hornung V, Bauernfeind F, Halle A, Samstad EO, Kono H, Rock KL, et al. Silica crystals and aluminum salts activate the NALP3 inflammasome through phagosomal destabilization. Nat Immunol. 2008; 9:847-56. [PubMed: 18604214]

78. Cruz CM, Rinna A, Forman HJ, Ventura AL, Persechini PM, Ojcius DM. ATP activates a reactive oxygen species-dependent oxidative stress response and secretion of proinflammatory cytokines in macrophages. J Biol Chem. 2007; 282:2871-9. [PubMed: 17132626]

79. Sansonetti PJ. The innate signaling of dangers and the dangers of innate signaling. Nat Immunol. 2006; 7:1237-42. [PubMed: 17110939]

80. Schwartz T, Behlke J, Lowenhaupt K, Heinemann U, Rich A. Structure of the DLM-1-Z-DNA complex reveals a conserved family of Z-DNA-binding proteins. Nat Struct Biol. 2001; 8:761-5. [PubMed: 11524677]

81. Deigendesch N, Koch-Nolte F, Rothenburg S. ZBP1 subcellular localization and association with stress granules is controlled by its Z-DNA binding domains. Nucleic Acids Res. 2006; 34:500720. [PubMed: 16990255]

82. Kim YG, Muralinath M, Brandt T, Pearcy M, Hauns K, Lowenhaupt K, et al. A role for Z-DNA binding in vaccinia virus pathogenesis. Proc Natl Acad Sci U S A. 2003; 100:6974-9. [PubMed: 12777633]

83. Takaoka A, Wang Z, Choi MK, Yanai H, Negishi H, Ban T, et al. DAI (DLM-1/ZBP1) is a cytosolic DNA sensor and an activator of innate immune response. Nature. 2007; 448:501-5. [PubMed: 17618271]

84. Ishii KJ, Kawagoe T, Koyama S, Matsui K, Kumar H, Kawai T, et al. TANK-binding kinase-1 delineates innate and adaptive immune responses to DNA vaccines. Nature. 2008; 451:725-9. [PubMed: 18256672]

85. Koyama S, Ishii KJ, Kumar H, Tanimoto T, Coban C, Uematsu S, et al. Differential role of TLRand RLR-signaling in the immune responses to influenza A virus infection and vaccination. $\mathrm{J}$ Immunol. 2007; 179:4711-20. [PubMed: 17878370]

86. Kanzler H, Barrat FJ, Hessel EM, Coffman RL. Therapeutic targeting of innate immunity with Toll-like receptor agonists and antagonists. Nat Med. 2007; 13:552-9. [PubMed: 17479101] 


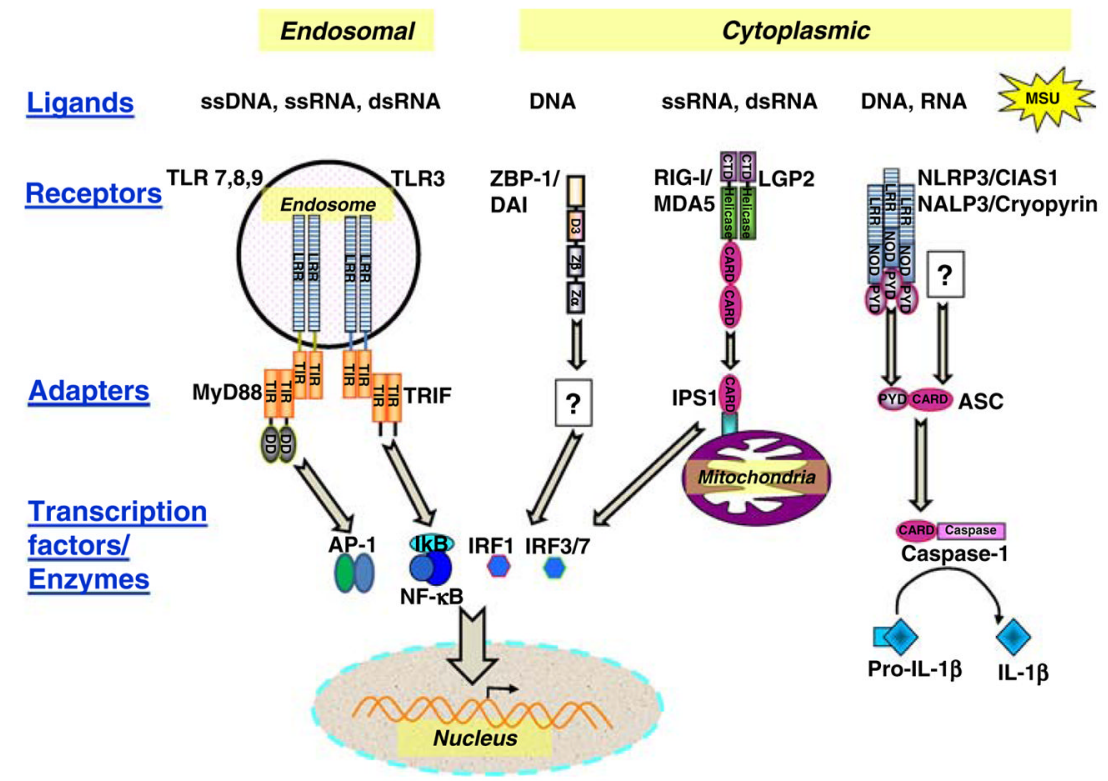

Fig. 1.

Recognition of nucleic acids by receptors/sensors of the innate immune system. Several families of receptors/sensors respond to nucleic acids in different subcellular compartments. This recognition triggers adapter protein-mediated signaling pathways that eventually lead to activation of transcription factors or caspases. TLR7 and 8 can also be activated by small nucleoside analogs not illustrated here. NLRP3 responds to a variety of other endogeneous, microbial, and environmental stimuli besides nucleic acids. Unknown receptors/sensors/ adapters are marked with question marks. The abbreviations are: LRR, leucine-rich repeats; TIR, Toll/interleukin-1 receptor; DD, death domain; Z $\alpha / Z \beta$, Z-DNA binding domain $\alpha / \beta$; $\mathrm{D} 3$, domain 3 (for DNA binding); CARD, caspase activation and recruitment domain; Helicase, RNA helicase domain; CTD, C-terminal domain; PYD, pyrin domain; NOD, nucleotide-binding and oligomerization domain; MSU, mono-sodium urate 